\section{Combined phlebography and arthrography in patients with painful swollen calf}

Anticoagulant treatment is potentially hazardous ${ }^{1}$ and, since the commonest reason for anticoagulation in hospital is the treatment of deep vein thrombosis, it is of paramount importance that the diagnosis be correctly established. Ruptured Baker's cyst (pseudothrombophlebitis syndrome) is a well-recognised cause of confusion in the diagnosis of deep vein thrombosis. Many workers have emphasised the need for a high index of clinical suspicion combined with either phlebography or arthrography in the differential diagnosis of the two conditions. Results of this study suggest that both phlebography and arthrography are essential for an accurate diagnosis to be reached.

\section{Patients, methods, and results}

Five men and five women aged 50-66 (mean 58) years were studied after referral to hospital because of a swollen, painful calf. All 10 patients had a history of painful stiff joints over a period ranging from three weeks to 15 years. Four patients had previously been diagnosed as having rheumatoid arthritis. The duration of the calf pain and swelling ranged from two to 10 days, and all patients were fully mobile on admission. In four patients the left calf was affected and in six the right calf. None had pain or swelling in or above the knee, and only one patient had a palpable popliteal swelling.

Initial diagnosis and presence or absence of deep vein thrombosis on phlebography, arthrography, and estimation of rheumatoid factor

\begin{tabular}{|c|c|c|c|c|}
\hline Case No & $\begin{array}{l}\text { Clinician's } \\
\text { diagnosis }\end{array}$ & Phlebography & Arthrography & $\begin{array}{l}\text { Rheumatoid } \\
\text { factor }\end{array}$ \\
\hline 1 & Baker's cyst & - & $+R^{*}$ & + \\
\hline 2 & Deep vein thrombosis & + & + & + \\
\hline 3 & Deep vein thrombosis & - & + & + \\
\hline 4 & Baker's cyst & + & $+\mathbf{R}^{*}$ & - \\
\hline 5 & Deep vein thrombosis & - & $+\mathbf{R}^{*}$ & + \\
\hline 6 & Deep vein thrombosis & - & $+\mathrm{R}^{*}$ & + \\
\hline 7 & Baker's cyst & + & & + \\
\hline 8 & Deep vein thrombosis & - & $+R^{*}$ & - \\
\hline 9 & Baker's cyst & - & - & + \\
\hline 10 & Baker's cyst & + & - & + \\
\hline
\end{tabular}

$* \mathbf{R}=$ Ruptured cyst.

All patients were examined on admission, the clinical diagnosis was noted, and blood was taken for estimation of rheumatoid factor. The patients underwent phlebography ${ }^{2}$ on the first day after admission to exclude the appearance of deep vein thrombosis secondary to bed rest in hospital. Immediately thereafter arthrography was carried out on the affected side. Films were obtained after injection and after active exercise (table). In only one out of 10 patients was the original clinical diagnosis correct. Three patients had both a deep vein thrombosis and a Baker's cyst.

\section{Comment}

Katz et $a l^{3}$ showed the necessity of maintaining a high index of clinical suspicion for both deep vein thrombosis and Baker's cyst in a group of arthritic patients. They noted certain clinical features that had proved helpful in differentiating these two groups within a large study of 62 patients. Layfer and Jones ${ }^{4}$ suggested that inflammation of the knee joint was a helpful pointer to a ruptured popliteal cyst, but this was not found by MacFarlane and Bacon. ${ }^{5}$ In our series of patients with joint symptoms and swollen calves the clinical symptomatology was singularly unhelpful. The diagnosis was incorrect in nine of the 10 patients. The one patient with a palpable popliteal swelling had both a deep vein thrombosis and a Baker's cyst. We were also unable to differentiate rupture of the cyst from an intact cyst by the signs of inflammation on clinical examination, as suggested by Katz et al. ${ }^{3}$ It is still common to find a patient with a swollen calf being treated according to clinical assessment alone.

It has been suggested that patients with arthritis, perhaps because of salicylate treatment, are protected from deep vein thrombosis. Our results, however, suggest that deep vein thrombosis may occur in such patients.

We emphasise that any patient with a history of joint pain who develops a swollen calf should undergo both phlebography and arthrography. We have shown that deep vein thrombosis and Baker's cyst may occur concurrently and that the diagnosis of one does not exclude the presence of the other.

1 Lowe GDO, McKillop JH, Prentice AG. Fatal retroperitoneal haemorrhage complicating anticoagulant therapy. Postgrad Med 1979;55:18-21.

2 Barrie WW, Wood EH, Crumlish P, Forbes CD, Prentice CRM. Lowdosage Ancrod for prevention of thrombotic complications after surgery for fractured neck of femur. $B r$ Med $\mathcal{F} 1974$;iv:130-3.

${ }^{3}$ Katz RS, Zizic TM, Arnold WP, Stevens MB. The pseudothrombophlebitis syndrome. Medicine $1977 ; 56(2): 151-64$.

4 Layfer LF, Jones JV. Calf pain in rheumatoid arthritis. IMF 1979;155(2): 104-5.

5 MacFarlane DG, Bacon PA. Popliteal cyst rupture in normal knee joints. Br MedF 1980 ;281 :1203-4.

(Accepted 19 December 1980)

University Department of Medicine and Department of Radiology, Royal Infirmary, Glasgow G4 OSF

J J F BELCH, MB, MRCP, honorary registrar

N C MCMILLAN, MB, DMRD, senior registrar in radiology

I FOGELMAN, MB, MRCP, senior registrar

H CAPELL, MB, MRCP, consultant physician

C D FORBES, MD, FRCP, consultant physician

\section{Urinary tract infection due to laboratory-acquired Escherichia coli: relation to virulence}

Concern about potential hazards of laboratory-acquired infection has increased in recent years. We report what we believe to be the first proved example of a urinary tract infection due to a strain of Escherichia coli acquired in the laboratory.

\section{Case report and investigation}

A 23-year-old woman who worked in a microbiology research laboratory presented with symptoms of urinary tract infection. Four days earlier she had developed central low abdominal discomfort with dysuria. The urine was smoky brown, and haematuria became more distinct the next day. Frequency and a sensation of incomplete bladder emptying developed on the second day. There was no loin pain, fever, or rigor. Symptoms continued for three days until she took Cystopurine (containing hexamine and sodium acetate), when symptoms subsided. Past medical history was not relevant and this was her first episode of urinary tract infection. Intercourse had taken place within 24 hours of the onset of symptoms. Cystitis was diagnosed, she was treated with co-trimoxazole two tablets twice daily for seven days, and recovery was uneventful.

Urine contained erythrocytes, more than 10 pus cells/high-power field numerous bacilli, and yielded a pure growth of $E$ coli $\left(>100 \times 10^{9} / 1\right)$. The organism was examined in detail and discovered to be identical with a standard laboratory strain, $E$ coli SP88, which had been isolated two years before from the urine of a child with urinary tract infection. The strain of $E$ coli isolated from the patient was compared with the standard laboratory strain and showed an identical API 20E profile (5044552); when tested by API $50 \mathrm{E}$ the profiles were identical at 24 hours, but after 48 hours the laboratory strain fermented starch and dulcitol, while the patient's strain failed to do so. The antibiotic susceptibility of the two strains was identical Neither strain was typable with $E$ coli 0 and $\mathrm{K}$ antisera but both had the flagellar serotype $\mathrm{H} 45$. Both strains adhered to human uroepithelial cells, and in neither case was the adherence inhibited by $1 \%(\mathrm{w} / \mathrm{v})$ mannose. Neither strain agglutinated guinea-pig erythrocytes, but human erythrocytes were agglutinated and haemagglutination was not inhibited by mannose.

These results indicated that both strains carried only mannose-resistan pili (fimbriae) (S N Abraham, S H Parry, M Sussman, in preparation). These were examined serologically and shown to have the identical pilus serotype $(a b)$. Finally the plasmid profile of the two strains was compared by a modification (I $M$ Feavers, $M$ Nahaie, D Owen, $C R$ Harwood, in preparation) of the method of Wilson et al ${ }^{1}$ with $E$ coli PVA 517 as standard. The strains were identical, and each carried seven plasmids (molecular weights $60,41,13,7 \cdot 6,3 \cdot 3,2 \cdot 6$, and 1.9 megadaltons respectively).

\section{Comment}

To establish that the patient's infection was laboratory acquired it was necessary to show that the laboratory strain with which she was working was identical with the strain isolated from her urine. 